\title{
Cryopreservation and transfer of pig embryos
}

\author{
R.D.A. Cameron', L.F.S. Beebe ${ }^{2}$ and A.W. Blackshaw ${ }^{1}$ \\ 'School of Veterinary Science, The University of Queensland, Brisbane, Australia 4072; \\ 2 Department of Obstetrics and Gynaecology, The University of Adelaide, South Australia 5005
}

Recent advances in cryopreservation and non-surgical transfer of pig embryos have made embryo transfer in pigs a commercially viable technology especially for the international transfer of valuable genetic material. Early research demonstrated that early stage pig embryos were highly sensitive to temperatures below $15^{\circ} \mathrm{C}$ and this sensitivity decreased with development to peri-hatching blastocysts which is accompanied by a reduction in lipid content. Removal of the lipid prior to freezing was found to improve the freezability and resulted in the birth of piglets. It was shown that by polarising the lipid material out of the blastomeres and using ultra rapid freezing (vitrification) the early stage zona pellucida intact embryo would also survive freezing and result in the birth of piglets. Other factors that have contributed to successful cryopreservation of the early stage pig embryo include the use of cytoskeletal stabilising agents, specific cryoprotectants, increasing cooling rates using open pulled straws or micro droplets and assisted hatching. The present review discusses the relative importance of each of these factors. The development of non-surgical transfer technology and its importance in the application of embryo transfer in the pig industry is also reviewed.

\section{Introduction}

Embryo transfer in pigs has been carried out for more than 50 years but only recently has it become a commercially viable technology available to the pig industry. This is the result of advances in cryopreservation, in particular vitrification and improvements in non-surgical embryo transfer technology. Commercialisation of embryo transfer in the pig industry has been greatly limited because of the difficulty in freezing the early stage zona pellucida intact embryo. Embryos for international transfer require an intact zona pellucida, which acts as an effective barrier to infection.

Another limiting factor in commercial application has been the need to transfer embryos surgically. On-farm transfers require acceptable surgical facilities as well as an experienced surgical team adding significantly to the cost. By overcoming these two main limiting factors the potential benefits of embryo transfer to the pig industry are of great significance. Undoubtedly the most important benefit is the ability to transfer entire maternal genetic material internationally or farm-to-farm with minimal risk of transfer of disease. Unique genetic lines can also be preserved by storage in liquid nitrogen which would guarantee biosecurity of specific nucleus stock. Dobrinsky (2000) stated that the long term preservation of pig embryos would also allow rapid regeneration or expansion of new and existing lines, the ability to increase 
selection pressure in nucleus herds, extraction or rescue of healthy stock from diseased herds and improve or eliminate quarantine conditions.

Dobrinsky (1996) described the cellular changes associated with the hypothermic sensitivity of pig embryos; an understanding of which has greatly contributed to advances in their successful cryopreservation. Similarly the development of methods of non-surgical transfer has been reviewed (van der Lende and Hazeleger, 1998; Hazeleger and Kemp, 2001).

These reviews detailed research carried out between 1972 and 1994 and will only be summarised here. The emphasis in this review will be to discuss more recent research developments that have contributed to the advances in cryopreservation and non-surgical transfer now making embryo transfer in pigs a commercially viable technology.

\section{Slow cooling/conventional freezing of pig embryos}

Early studies of cooling pig embryos to temperatures between $20^{\circ} \mathrm{C}$ and $5^{\circ} \mathrm{C}$ clearly demonstrated that the pig embryo is highly sensitive to temperatures below $15^{\circ} \mathrm{C}$ (Wilmut, 1972 ; Polge et al., 1974). These workers suggested that this sensitivity was due to intracellular lipid or to lipid phase changes within the plasma membranes of blastomeres.

Following these earlier studies a number of reports using the slow conventional method of freezing provided further insight into the freezability of the pig embryo summarised as follows:

- Pig embryos are highly sensitive to temperatures below $15^{\circ} \mathrm{C}$ and the sensitivity to low temperatures decreases with increasing stage of development (Nagashima et al., 1988).

- Peri-hatching and hatched blastocysts will survive freezing to $-196^{\circ} \mathrm{C}$ (Nagashima et al ., 1989).

- Maximum freezability peaks immediately post-hatching when the diameter of the blastocysts is between 150 and $300 \mu \mathrm{m}$ (Nagashima et al., 1992).

- The composition of pre-culture medium may influence the freezability and thus the survival rate of expanding and hatched blastocysts (Thomas and Hillman, 1980; Nagashima et al., 1992).

- Birth of piglets can result from expanded blastocysts cooled to $-35^{\circ} \mathrm{C}$ and/or followed by plunging into $\mathrm{LN}_{2}$ (Hayashi et al., 1989; Feng et al., 1991; Kashiwazaki et al., 1991).

\section{Freezability of delipated embryos}

The high concentration of lipid droplets found in pig embryos is considered to be associated with their sensitivity to temperatures below $15^{\circ} \mathrm{C}$ (Wilmut, 1972; Polge et al., 1974; Polge, 1977; Polge and Willadsen, 1978). This theory was given support by the fact that as the lipid content in pig embryos decreased with development, the late stage peri-hatching blastocysts became less sensitive to cooling and could survive freezing and storage in liquid nitrogen at $196^{\circ} \mathrm{C}$ (Niimura and Ishida, 1980; Nagashima et al., 1988; Nagashima et al., 1989; Kashiwazaki et al., 1991). Injury associated with freezing and thawing is considered to be due to physicalchemical events such as ice formation within cells, concentration of intra and extra-cellular electrolytes and osmotic trauma (Mazur, 1977). The lethal effect of cooling on pig embryos however occurs just below $15^{\circ} \mathrm{C}$ and is not associated with freezing.

With this in mind Nagashima et al., (1994) suggested that removal of the lipid droplets should reduce their sensitivity to chilling. They collected 1-cell and 2-4 cell embryos and fully or partially removed the lipid droplets (delipated) by centrifugation to polarise the lipid granules that were partially or totally removed using a micromanipulator. The embryos were chilled 
to $4^{\circ} \mathrm{C}$ for $1 \mathrm{~h}$, rewarmed to $37^{\circ} \mathrm{C}$ and then cultured. Embryos that cleaved at least once were considered surviving. Of the fully delipated 1 cell or $2-4$ cell embryos more than $60 \%$ cleaved and developed beyond the 8 cell stage. Control embryos (chilled intact) lysed and none of the sham-operated embryos developed beyond the 8 cell stage. Partially delipated embryos also survived chilling, however few developed beyond the 8 cell stage and even less to the blastocyst stage.

This report demonstrated that pig embryos gain tolerance to chilling when their lipid content is reduced. The authors suggested that the chilling damage suffered may be due to phase separation in the plasma and/or internal membranes. It has been suggested that the sensitivity to chilling could be due to irreversible changes in membrane structure (Edidin and Petit, 1977) such as lateral phase separation of membrane lipids. Lipid droplets not only may play a role in providing a nutrient source but may also be important in modifying the physical properties and function of membranes. Nagashima et al., (1994) suggested that reducing the amount of lipid droplets may result in changes in membrane lipid content which may in turn limit the extent of phase separation and the resulting damage. It was reported that when pig embryos are held at $15^{\circ} \mathrm{C}$ structural changes take place within the lipid droplets so that they coalesced to form larger droplets (Edidin and Petit, 1977). As the droplets are surrounded by endoplasmic reticuium a loss of cytoplasmic organisation may result in irreversible damage to the embryo (Mohr and Trounson, 1981).

A subsequent report by Nagashima et al., (1995a) described the birth of 3 piglets following the transfer of 39 cryopreserved delipated embryos to one recipient. This was the first report of early stage zona pellucida intact pig embryos cryopreserved in liquid nitrogen resulting in the birth of piglets following thawing and transfer.

Although this was a major advance in the development of cryopreservation of pig embryos, it would have little if any practical application in commercial embryo preservation and transfer because of the laborious and skilful micromanipulation procedure required. Further, the procedure involved penetration of the zona and therefore such embryos were strictly not zona intact; a requirement for international transfer.

Nagashima et al., (1994) stated that development of a non-invasive means of lipid removal may provide one method of overcoming current limitations of cryopreserving pig embryos. In a later report Nagashima et al., (1999) froze morulae and early blastocysts following centrifugation to reduce the lipid content in their cytoplasm. The lipid was dispersed in the perivitelline space during freezing and thawing, but some lipid droplets redistributed into the blastomeres during freezing and thawing. As a result the embryos were considered incompletely delipated and not fully cryo-tolerant. The authors suggested this may be overcome by ultra-rapid freezing or vitrification.

\section{Vitrification}

In 1985 Rall and Fahy described a method of producing ice-free cryopreserved mouse embryos at $-196^{\circ} \mathrm{C}$ by vitrification. This method relies on the ability of highly concentrated aqueous solutions of cryoprotective agent to supercool to low temperatures whereby they become so viscous that they solidify without the formation of ice, a process called vitrification. The solid, called a glass, retains the normal molecular and ionic distribution of the liquid state and is therefore considered to be an extremely viscous supercooled liquid devoid of all ice crystals (Rall, 1987). Embryos cooled by vitrification are not damaged by ice crystal formation (Rall and Fahy, 1985).

Several physical-chemical and cryobiological factors were considered important for the suc- 
cessful preservation of embryos by vitrification Rall (1987). Vitrification requires the use of highly concentrated yet non-toxic solutions of cryoprotectants. Embryos undergo dehydration prior to cooling by stepwise exposure to permeating cryoprotectants under conditions in which only part of the cryoprotectant enters the cell. This results in shrunken cells in which both the endogenous cytoplasmic solutes and the intra-cellular cryoprotectants are concentrated by osmotic loss of water. These embryos will survive vitrification when cooled at rates between 15 and $2500^{\circ} \mathrm{C}$ per minute and warmed between 200 and $2500^{\circ} \mathrm{C}$ per minute. When warmed, due to the presence of intracellular cryoprotectant the embryo is susceptible to excessive osmotic swelling. Osmotic injury can be avoided when the embryos are diluted from the vitrification solution by either a slow stepwise procedure or a sucrose dilution procedure.

The advantages of cryopreservation by complete vitrification of the embryo suspension are firstly, it alleviates concern for the potentially damaging effects of intra or extracellular crystallisation, and secondly the embryos are exposed to less concentrated solutions of cryoprotectants for shorter periods of time (Rall, 1987). Further, unlike conventional procedures that employ freezing, vitrification does not require cooling and warming at 'optimum' rates. Cooling and warming need only be rapid enough to prevent crystaltisation.

Following a report by Arav et al., (1990) of the successful vitrification of immature pig oocytes, it was suggested by Niemann (1991) that further investigations should be undertaken to develop freezing techniques for zona pellucida intact pig embryos. Pollard and Leibo (1994) suggested that it may be possible to 'out race' chilling injury by sufficiently rapid cooling in a fashion analogous to that found to apply to embryos of Drosophila an insect species extremely sensitive to chilling. Like pig embryos Drosophila embryos contain large amounts of lipid (Mazur et al., 1992) but can survive cryopreservation by vitrification (Steponkus et al., 1990).

\section{Protocols for the successful vitrification of pig embryos}

A number of factors are considered important in the successful vitrification of pig embryos. They include:

- specific cryoprotective agents,

- cytoskeletal stabilising agents,

- polarising the lipid content before vitrification,

- increased cooling rates,

- assisted hatching,

- recognition of the importance of genotype.

However in many reports more than one of these factors was involved in successful vitrification protocols making it difficult to determine the individual contribution of each.

Evaluation of cryoprotective agents

Vitrification solutions contain cryoprotective agents that are organic solutes which protect intracellular organefles during freezing and long term storage in $\mathrm{LN}_{2}$. Permeating cryoprotective agents intracellularly interact to influence cellular microfilament and microtubule dynamics (Dobrinsky, 1996). The interaction between cryoprotectants and cellular organelles and the cytoskeleton of embryos is not consistent across species (Parks and Ruffing, 1992). Embryo survival also depends on the type of cryoprotectant and stage of development. 
A number of early studies demonstrated that some vitrification solutions can be extremely toxic to pig embryos (Weber et al., 1992; Dobrinsky and Johnson, 1993). Weber et al., (1992) evaluated three different vitrification solutions for pig embryos, consisting of combinations of propylene glycol, glycerol and ethylene glycol and considered all to be either toxic or to provide inadequate cryoprotection to enable the successful birth of piglets from vitrified embryos. However in 1994 Kobayashi et al., reported the successful vitrification of pig embryos in ethylene glycol, polyvinylpyrrolidone (PVP) and galactose demonstrating that pig embryos will tolerate exposure to high concentrations of ethylene glycol and PVP and that rapid cooling can circumvent their extreme sensitivity to chilling.

In 1994 Dobrinsky and Johnson compared in vitro development of various stages of pig embryos using three different vitrification solutions. The solutions contained glycerol/propylene glycol, ethylene glycol/bovine serum albumin (BSA) or glycerol and BSA. The glycerol/ BSA vitrification solution resulted in a higher percentage of embryo survival which was related to the age and stage of development. No day 5 morulae/blastocysts survived whereas $27 \%$ of day 6 blastocysts/expanded blastocysts and $39 \%$ of day 7 hatched blastocysts survived in vitro for at least 24 hours.

In an experiment to examine the effect of glycerol, with or without sucrose, Nagashima et al., (1995b) using a conventional slow cooling method found better survival rates when using sucrose. Transfer of 66 embryos from the glycerol and sucrose cryopreserved embryos to 3 recipients after thawing resulted in the birth of 4 piglets. Nagashima et al., (1999) also successfully vitrified $2-4$ cell embryos using $40 \%$ ethylene glycol, $1 \mathrm{M}$ sucrose and $20 \%$ foetal calf serum (FCS) as the cryoprotectant.

Using a vitrification solution consisting of $30 \%$ ethylene glycol, $1 \mathrm{M}$ sucrose, $5 \%$ egg yolk and $20 \%$ calf serum Kuwayama et al., (1997) demonstrated that all stages of pig embryos from morulae to hatched blastocysts survived vitrification. Also Kobayashi et al., (1998) using ethylene glycol and PVP transferred 64 vitrified/warmed expanded and hatched blastocysts to three recipients. Two recipients became pregnant, one farrowed four normal piglets, the other aborted at 65 days gestation. More recently, Berthelot et al., $(2001 ; 2002)$ produced live piglets from vitrified pig embryos using dimethy! sulphoxide (DMSO) and ethylene glycol as the cryoprotectant.

These studies have resulted in 3 cryoprotectants, ethylene glycol, DMSO and glycerol now commonly being used for vitrification of pig embryos. Reports of the birth of piglets following vitrification using these cryoprotectants are summarised in Table 1.

\section{Use of cytoskeletal stabilising agents}

In 1996 Dobrinsky outlined the basis for the cellular approach to cryopreservation of embryos by demonstrating cellular disruption in cryopreserved embryos and the utilisation of cytoskeletal stabilisation, by treatment with cytochalasins, prior to cryopreservation, to deter cellular disruption. If the cytoskeleton is disrupted the mitotic cell cycle will cease, functional complexes may be compromised and solute transport systems affected (Dobrinsky et al., 2000).

When Nagashima et al., (1994) used centrifugation to polarise the lipid of early stage embryos they used cytochalasin-b to aid the lipid displacement. According to Mcgrath and Solter (1983) cytochalasin-b would make the plasma membranes less rigid and more elastic so that microfilaments are not disrupted during micromanipulation.

Cryoprotectants depolymerise microfilaments. This may be beneficial during osmotic stresses induced by exposure and/or removal of cryoprotectants. Cytochalasin-b was used by Dobrinsky et al., (2000) to depolymerise microfilaments in an attempt to improve survival rates of pig morulae, early blastocysts, expanded blastocysts or hatched blastocysts. Survival after vitrifica- 


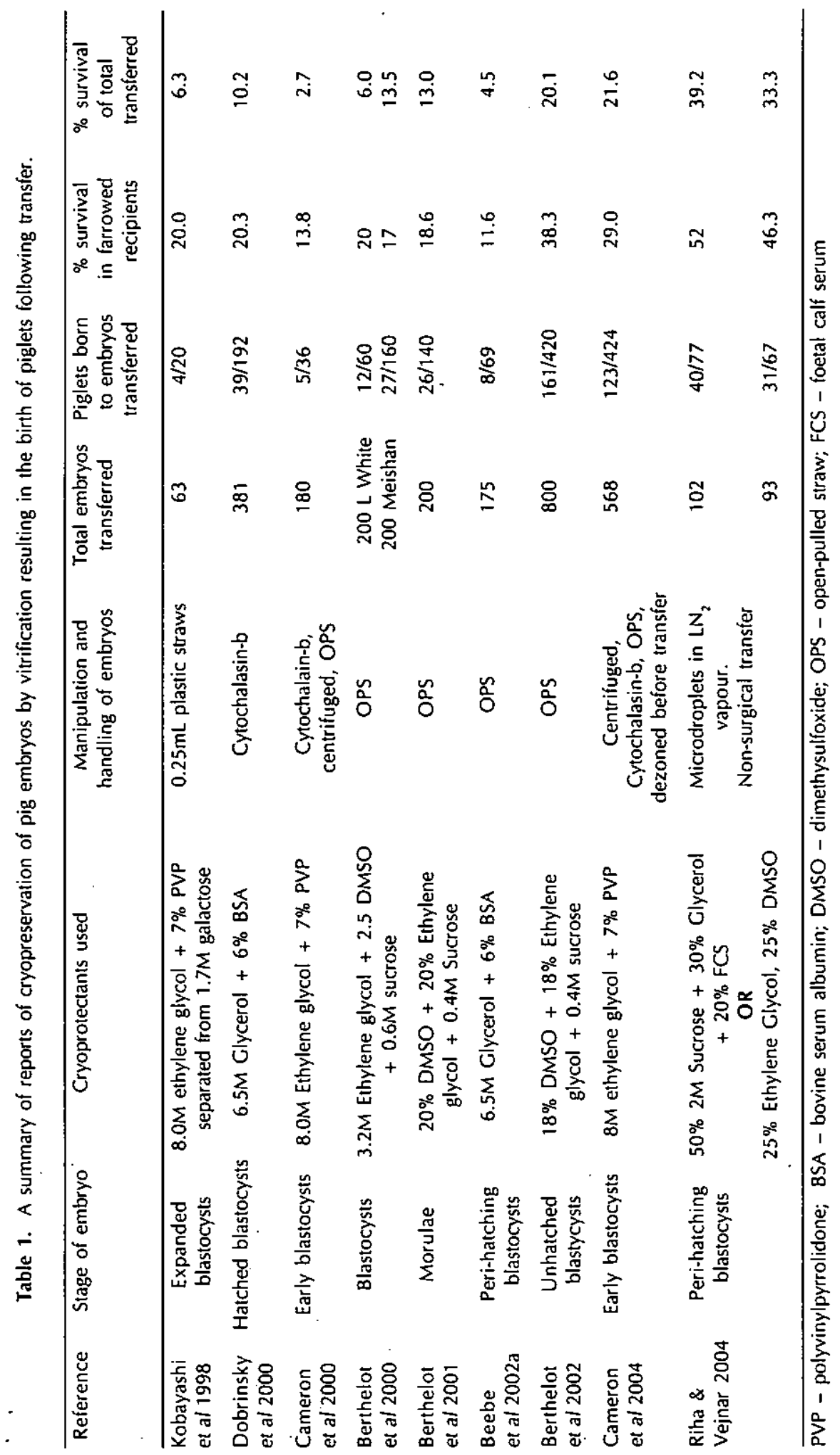


tion was based on development after in vitro culture or in vivo, following transfer to recipient gilts. The presence of cytochalasin-b during vitrification significantly improved the in vitro development of expanded blastocysts and hatched blastocysts with diameters $<400 \mu \mathrm{m}$, although expanded blastocyst viability was significantly lower than hatched blastocysts. Treatment with cytochasasin-b did not however improve the survival of morulae and early blastocysts.

Similarly, the development of hatched blastocysts with diameters $>400 \mu \mathrm{m}$ was not improved by the presence of cytochalasin-b. Cellular analysis with laser scanning confocal microscopy showed that the cytoskeleton can be affected during cryopreservation and that microfilament depolymerisation prior to vitrification significantly improved expanded and hatched blastocyst development.

In vivo development was assessed by transfer to recipients of hatched blastocysts vitrified in the presence of cytochalasin-b in two trials (Dobrinsky et al., 2000). Transfer of a total of 180 embryos to 11 recipients resulted in the birth of 39 piglets. Since this report there are now a number of reports of successful production of piglets from early stage vitrified embryos using cytochalasin-b in order to depolymerise the cytoskeleton before centrifugation to polarise the lipid material (Beebe et al., 2002a; Cameron et al., 2000; 2004).

It would appear that cytochalasin-b is beneficial both when using centrifugation of early stage embryos to polarise the lipid and for improving the survival of cryopreserved peri-hatching embryos.

\section{Polarisation of lipid before vitrification}

Nagashima et al., (1999) suggested that vitrification or ultra rapid freezing may overcome the problem of lipid redistributing back to the cytoplasm of some cells immediately following centrifugation.

In 2000 Beebe et al., reported the results of experiments demonstrating the successful vitrification of early zona pellucida intact blastocysts in vitro and in vivo. The vitrification method used ethylene glycol as the cryoprotectant, culture medium containing cytochalasin-b and centrifugation to polarise the lipid material before vitrification in open-pulled straws (OPS). In a preliminary in vitro study, 23 out of $30(77 \%)$ embryos centrifuged before vitrification survived in culture. None out of 25 embryos survived vitrification without prior centrifugation. The transfer of embryos centrifuged before vitrification to five recipients resulted in one of the five farrowing five piglets. This was the first report of piglets born from vitrified early blastocysts surrounded by an intact zona pellucida. It was also the first report where vitrification involved the combined use of cytochalasin-b, centrifugation and OPS. These preliminary in vitro results clearly demonstrated the value of centrifugation to polarise the lipid prior to vitrification.

Increasing cooling rates using open pulled straws

The use of the OPS method has been described by Vajta et al., (1997a, 1997b and 1998). The method involves heat-softening and manual pulling of French mini straws reducing both the outer and inner diameter by approximately half. By using these ultra thin and open straws during vitrification the freezing and thawing rates of medium $(\cong 0.5 \mu \mathrm{L})$ surrounding embryos is increased to about $22,000^{\circ} \mathrm{C}$ per minute compared with $2,500^{\circ} \mathrm{C}$ per minute in the original straw (Vajta et al., 1998). The critical damaging temperature zone is transversed rapidly minimising chilling injury and because the straws are open ended no pressure changes occur during freezing avoiding fracture damage (Vajta et al., 1997a). Additional benefits include minimisation of the volume of the cryoprotectant exposed to the embryos in the straw, thus reducing the toxic and osmotic effects at thawing by rapid immersion of the embryo-containing 
capillary into a thawing solution. Rehydration of embryos occurs immediately after immersion into the thawing solution (Vajta et al., 1997a). Further, using the OPS method significantly reduced or completely eliminated fracturing of the zona pellucida which is common in conventionally frozen embryos (Vajta et al., 1998).

Using the OPS method Vajta et al., (1997b) successfully vitrified pig embryos, based on in vitro survival following warming and culture. The overall survival of compacted morulae to expanded blastocysts was $48 / 52(91 \%)$ and the hatching rate was $67 \%$. Using OPS for vitrification, other workers have successfully produced piglets (see Table 1).

Beebe et al., (2002a) compared the in vitro survival of peri-hatching blastocysts vitrified using heat-sealed straws with those using OPS. Freezing in OPS significantly improved survival rate compared with freezing in heat sealed straws. The birth of live piglets following the transfer of vitrified/warmed morulae/early blastocysts using OPS, cytochalasin-b and centrifugation to polarise the lipid was reported by Beebe et al (2002b).

Kobayashi et al., (2003) also reported the birth of 12 piglets from the transfer of expanded and hatched blastocysts vitrified in OPS. Four recipients received 20 to 23 embryos per recipient. Three became pregnant, one aborted and the remaining two farrowed litters of four and eight piglets.

\section{Increasing cooling rates - other options}

The successful production of live piglets following transfer of vitrified embryos using the OPS method supports the view that cooling rate is one of the most important factors in the survival of vitrified pig embryos. A number of other methods have been developed to further increase cooling rates during vitrification. These include the use of super fine OPS (SOPS) (Isachenko et al., 2003); applying a negative pressure (vacuum) to the surface of liquid nitrogen to lower its boiling point from $-196^{\circ} \mathrm{C}$ to below $-204^{\circ} \mathrm{C}$, (Arav et al., 2000; Beebe et al., 2002b), or placing embryos in microdroplets (Lane et al., 1999; Misumi et al., 2003; Lindemans et al., 2004).

A comparative study of in vitro survival rates and cell counts of morulae and early blastocysts vitrified using OPS plunged directly into liquid nitrogen or liquid nitrogen held under a vacuum (VitMaster, Minitube USA) was reported by Beebe et al., (2002b). The survival rates and cell counts for the embryos vitrified in the Vit Master were significantly greater than embryos plunged directly into liquid nitrogen. Rates of cooling using the OPS method alone are about $22,000^{\circ} \mathrm{C}$ per minute whereas the rate for the Vit Master is up to $135,000^{\circ} \mathrm{C}$ per minute.

A similar study (Cuello et al., 2004a) compared the survival rate and hatching rate of morulae, early blastocysts and expanded blastocysts vitrified using OPS or SOPS cooled in a Vit Master. Although they found the developmental stage of the embryos affected their survival and hatching rates, the three vitrification systems and interaction with embryonic stage of development had no significant effect on in vitro survival or hatching rate. This study suggested that any increase in cooling rates above $20,000^{\circ} \mathrm{C}$ per minute did not enhance the efficiency of survival rate or hatching of morulae or blastocysts. Nevertheless as was suggested, cooling rates above $20,000^{\circ} \mathrm{C}$ per minute may enable the use of lower cryoprotectant concentrates thus reducing their toxicity.

A number of reports have described the use of microdroplets to vitrify bovine embryos. These systems involved plunging the microdroplet containing the embryos directly into liquid nitrogen. (Lane et al., 1999; Papis et al., 2000) or cooling the droplet on a metal surface pre-cooled with liquid nitrogen a process called solid surface vitrification (SSV) (Dinnyes et al., 2000; 2003; Lindemans et al., 2004).

A recent report described the successful vitrification of pig morulae and early blastocysts using a micro droplet method (Misumi et al., 2003). Microdroplets have the advantage of being a containerless system eliminating any insulating layer, coupled with a small volume of medium 
$(<1 \mu \mathrm{L})$ resulting in rapid and uniform heat exchange during cooling. Microdroplets placed on a solid surface have the added advantage of no exposure to the liquid nitrogen, eliminating the risk of embryo contamination.

In 2004 Riha and Venjar reported vitrification of peri-hatching blastocysts using a micropipette to transfer and store embryos into LN2 vapour in microdroplets. They achieved pregnancy rates of up to $66.7 \%, 7.8 \pm 1.26$ piglets born and $46.3 \%$ prenatal survival rate in recipients that farrowed.

There seems little doubt that the rate of cooling is a very important factor in the successful freezing of pig embryos. By accelerating the speed of temperature change it may be possible to eliminate the need to polarise the lipid and for cytochalasin-b when vitrifying the early stage pig embryo. It may also be possible to further decrease cryoprotectant concentrations. These factors would simplify cryopreservation of pig embryos making the procedure more acceptable for commercial application.

\section{The influence of genotype on freezability of pig embryos}

A number of studies have indicated that the genotype of the embryo donor can influence the freezability of pig embryos. Nagashima et al., (1992) using slow cooling found embryos collected from German Landrace gilts had a poor freezability compared with Landrace $x$ Large White hybrid gilts. Weber and Young (1994) concluded from their investigation of cryoprotectant toxicity to pig embryos that donor females can have a dramatic effect on tolerance to embryo cryopreservation procedures.

In France, Berthelot et al., (2000) using both hyperprolific Large White and Meishan donors and Meishan recipients found a significant breed difference in embryo survival following vitrification. Survival (in vitro hatching rate) of Meishan blastocysts after vitrification was $67 \%$ compared with $27 \%$ for Large White blastocysts. Further, the in vivo survival of vitrified/warmed Large White and Meishan embryos resulted in a farrowing rate of $80 \%$ for Meisham embryos compared with $30 \%$ for Large White embryos. In vivo embryo survival rates were $13.5 \%$ and $5.5 \%$ for Meishan and Large White respectively.

Cuello et al., (2004b) found the in vitro survival and hatching rate of expanded blastocysts graded as excellent or good on morphological appearance differed significantly between donors following vitrification and warming. This donor effect is in general agreement with Fujino et al., (2003) who demonstrated that embryos taken from one donor at the same time possess similar cryotolerance.

The implications of the influence of donor genotype on pig embryo freezability are obviously important not only for future research but for commercial application of embryo transfer in the pig industry.

White et al., (2005) compared the in vitro development following vitrification of zona pellucida intact embryos collected from Meishan and occidental White cross breeds. Vitrification was performed using microdroplets exposed to LN2 vapour and then plunged into LN2. The percentage of embryos surviving for 24 hours after cryopreservation was significantly higher for the Meishan $(72 \%)$ than the White cross embryos $(44 \%)$. However development at the expanded or hatched stages was not so different between the two breeds, indicating that Meishan embryos have a higher capacity to survive vitrification than White cross embryos.

These findings provide strong evidence that the freezability of embryos is directly related to genotype and this is likely to have important implications for predicting the outcome of commercial embryo transfer programmes using cryopreserved embryos.

\section{Assisted hatching}

Both Dobrinsky (2002) and Beebe et al., (2004) found that the hatching rate of pig morulae/ 
early blastocysts centrifuged, vitrified/thawed and cultured for more than 48 hours was low relative to the percentage of viable blastocysts with blastocoels at 48 hours. It was suggested that the polarised material left in contact with the blastomeres during vitrification may have some inhibitory effect following thawing and recovery.

To test whether centrifugation and the presence of the zona pellucida inhibit cryopreserved embryos from developing, Dobrinsky (2002) cryopreserved by conventional freezing or vitrification with or without centrifugation morulae/early pig blastocysts. After warming and rehydration the zona pellucida was removed and the embryos were cultured. The non-centrifuged cryopreserved embryos with intact zona used as controls did not develop in vitro. The centrifuged, cryopreserved embryos with zona removed developed at high rates into blastocysts after 72 hours, resembling hatched blastocysts. Further, to test in vivo development of centrifuged vitrified embryos with the zona removed after warming and rehydration they were transferred to 11 recipients. Nine of the 11 recipients farrowed $(82 \%)$ a total of 61 piglets averaging 7.0 piglets per litter. However no comparison was made of survival between vitrified zona intact and zona free embryos.

Beebe et al., (2004) assessed the opportunities to improve the vitrification protocol of pig embryos by removal or thinning of the zona pellucida post-warming before transfer (assisted hatching). One group of embryos was cultured with the zona intact, while another group had the zona removed with $0.5 \%$ pronase in PBS for 30 seconds then cultured for 24 hours. Viable embryos were fixed and the nuclei stained for cell count. Removal of the zona did not affect survival rates but increased cell count by $56 \%$. Further experiments found zona thinned embryos $(0.25 \%$ pronase for $10 \mathrm{sec})$ had the same survival rate and cell count as zona free embryos indicating that vitrified pig blastocysts benefit from assisted hatching whether the zona pellucida is removed or just thinned. This would suggest that the presence of the lipid material in the perivitelline space was not the reason for difficulty in hatching (Beebe et al., 2005)

\section{Commercial application of embryo transfer using early zona intact blastocysts}

Cameron et al., (2004) carried out a trial in 2002 to demonstrate the feasibility of using vitrified zona pellucida blastocysts to transfer genetic material from a commercial herd into a specific pathogen free herd, and achieved acceptable farrowing rates and litter size. The embryos were collected from weaned sows that had been oestrous synchronised and mated in the commercial herd and then transported $350 \mathrm{~km}$ by road to a dedicated embryo collection centre. The embryos collected surgically were vitrified following centrifugation in the presence of cytochalasin-b in OPS using a Vit Master.

A total of 568 embryos was transferred surgically to 21 recipients in the SPF herd and their accommodation, management and feeding was the same as for all other sows in the herd. Sixteen sows $(80 \%)$ were confirmed pregnant at 35 days and 15 sows farrowed $(75 \%)$. One sow died at 40 days gestation and at post-mortem was found to have 17 normal and 1 small foetus. A total of 125 piglets (mean 8.2) was born and 115 were born alive (mean 7.7). In the 15 sows that farrowed $29.0 \%$ of embryos survived to produce piglets, and if the sow that died had produced 17 piglets the survival rate would have been $34.5 \%$.

This study demonstrated that vitrified zona pellucida intact embryos can be used to move genetic material from farm-to-farm and possibly internationally with acceptable reproductive performance. Considering these results and results of other recent reports, embryo transfer in the pig industry using frozen embryos has reached a stage of viable commercial application at least for highly valued genetic material. 


\section{Non-surgical embryo transfer}

Traditionally, transfer of pig embryos to recipients has been carried out surgically. The most common method is to transfer the embryos to one uterine horn placing them just below the uterotubal junction (Cameron et al., 1989). This requires a general anaesthetic. The procedure, although it takes only about 20 minutes, must be carried out with strict asepsis. The requirements of sterile surgery are often difficult to achieve under farm conditions and present a number of logistical problems and expense to commercial 'on-farm' transfers. Therefore the need to develop a simple non-surgical method of transferring pig embryos has been recognised for many years.

The first pregnancies resulting from non-surgical transfer of pig embryos were reported by Polge and Day (1968). They transferred 8 to 16 cell embryos to 17 recipients. Three living embryos and four regressing embryos were found in one recipient when slaughtered 17 days after transfer.

In 1987 Sims and First reported the successful non-surgical transfer of day 7 post-oestrus embryos (presumably hatched blastocysts) using an insemination spirette catheter. Out of 21 transfers they obtained a total of 13 pregnancies. Reichenbach et al., (1993) reported the first non-surgical transfer of pig embryos resulting in the birth of live piglets.

Using a 3-way stopcock and a disposable Al spirette Galvin et al., (1994) transferred 4-cell to blastocyst stage embryos non-surgically. The recipients were lightly sedated during transfer. Out of 46 recipients receiving $11.8 \pm 0.5$ embryos $12(26 \%)$ were diagnosed pregnant at between 30 and 60 days and 10 recipients farrowed. The mean litter size was $4.3 \pm 0.7$. The authors were of the opinion that the small litter size was most likely due to the site of placement of the embryos. Nevertheless Polge (1977) found that 4-cell embryos could survive if transferred to the cervical end of the uterus.

Hazeleger and Kemp (1994) described a relatively simple instrument for non-surgical transfer to multiparous crossbred sows. This consisted of a PVC rod (length $1 \mathrm{~m}$, diameter $3 \mathrm{~mm}$ ) with a $90^{\circ}$ hook of $1 \mathrm{~cm}$ at one end. Connected to the side of the rod was a Teflon guiding tube. Together they were passed through the cervix into the uterine body. An embryo catheter was passed through the guiding tube into the uterine body with embryos in the tip. The embryos were flushed into the uterus with $0.1 \mathrm{~mL}$ of medium. Transfer of 14 to $21(17 \pm 2)$ embryos ranging in stages from morulae to blastocyst into each of 21 recipients resulted in 7 pregnant sows $(33 \%)$. The average litter size was $6.7 \pm 1.6$. The presence of blastocysts resulted in a $55 \%$ pregnancy rate compared to $10 \%$ in the absence of blastocysts. A higher percentage of non-pregnant recipients received no blastocysts. The inclusion of blastocysts confirms the results of Mödl et al., (1993) who also obtained a pregnancy rate of 55\% with non-surgical transfer.

Yonemura et al., (1996) used a rubber spiral catheter to transfer an average of $17.8 \pm 7.9$ embryos (ranging from morulae to hatched blastocysts) to a total of 25 recipients (synchronous or \pm 1 day). The farrowing rate was $64 \%$ (16 recipients farrowed an average of $3.1 \pm 1.6$ piglets). The high pregnancy rate may have been due to the larger volumes used ( $30 \mathrm{~mL}$ to $50 \mathrm{~mL}$ ) forcing the embryos further up the uterine horns. It is difficult to explain the low litter size in relation to pregnancy rate but it was considered to be due to the location of the embryos and subsequent distribution and possibly because some embryos were discharged back through the vagina.

For non-surgical transfers Li et al., (1996) developed an instrument consisting of 4 parts that allowed the embryos to be deposited into the lumen of one uterine horn. Five out of $16(31 \%)$ recipients farrowed an average of $6.2 \pm 3.11$ piglets per litter. The 5 farrowings were from recipients that received blastocysts and morulae or only morulae. 
Riha and Vejnar (2003) reported the results of non-surgical transfer of vitrified embryos to both sows and gilts. In sows they obtained a farrowing rate of $4 / 12$ and in gilts $4 / 16$. The average litter size for sows was $6.3 \pm 1.65$ and gilts $7.3 \pm 3.6$ total piglets born. The results of non-surgical transfer of fresh embryos given in the same report was a pregnancy rate of $12 / 25$ $(48 \%)$, farrowing rate $8 / 25(32 \%)$ with an average of $6.88 \pm 1.78$ piglets born per litter. In another report using two different vitrification media and transferring the embryos non-surgically Riha and Vejnar (2004) obtained an overall pregnancy rate of $69 \%$ and an average of 7.9 piglets born. In both reports the transferred embryos were expanded, hatching and/or hatched blastocysts.

The most recent report (Martinez et al., 2004) has resulted in the highest farrowing rates $(70.8 \%)$ and average litter size $(6.9 \pm 0.7)$ with non-surgical transfer of fresh morulae and/or blastocysts. These workers developed a catheter consisting of an Al spirette catheter for insertion into the cervix to be used to guide a flexible catheter into the uterine horn. This study reports a technique for non-surgical transfer of embryos deep into the uterine horn of both gilts and sows 4-6 days post-oestrus without sedation and with acceptable subsequent reproductive performance. However further studies need to be carried out under typical farm conditions and also using cryopreserved embryos.

Table 2. Summary of reports of non-surgical transfer of pig embryos resulting in the birth of piglets

\begin{tabular}{|c|c|c|c|c|c|c|}
\hline Reference & $\begin{array}{l}\text { Type of catheter } \\
\text { and restraint }\end{array}$ & $\begin{array}{l}\text { Embryo stage and } \\
\text { deposit site }\end{array}$ & $\begin{array}{l}\text { Volume of } \\
\text { flush medium } \\
\text { (ml) }\end{array}$ & $\begin{array}{l}\text { Pregnancy } \\
\text { rate } \%\end{array}$ & $\begin{array}{l}\text { Farrowing } \\
\text { rate \% }\end{array}$ & $\begin{array}{l}\text { Mean litter } \\
\text { size }\end{array}$ \\
\hline $\begin{array}{l}\text { Reichenbach } \\
\text { et al } 1993\end{array}$ & $\begin{array}{l}\text { Al spirette \& cannula } \\
\text { General anaesthetic }\end{array}$ & $\begin{array}{l}8 \text { cell to HB } \\
\text { Body of uterus }\end{array}$ & $10-20$ & 10.3 & 5.2 & 5 \\
\hline $\begin{array}{l}\text { Galvin } \\
\text { et al } 1994\end{array}$ & $\begin{array}{c}\text { Al spirette \& } 3 \text { way stopcock } \\
\text { Lightly sedated }\end{array}$ & $\begin{array}{c}4 \text { cell to B } \\
\text { Body of uterus }\end{array}$ & $\begin{array}{l}10-12 \\
\& 15 \text { air }\end{array}$ & 26.0 & 21.7 & $4.3 \pm 0.7$ \\
\hline $\begin{array}{l}\text { Hazeleger } \\
\text { \& Kemp } 1994\end{array}$ & $\begin{array}{c}\text { PVC rod \& guiding tube } \\
\text { \& catheter }\end{array}$ & $\begin{array}{c}\text { M to B } \\
\text { Body of uterus }\end{array}$ & 0.1 & 33.3 & 33.3 & $6.7 \pm 1.6$ \\
\hline Li et al 1996 & $\begin{array}{l}3 \text { part transcervical unit } \\
\text { \& soft plastic embryo carrier } \\
\text { General anaesthetic }\end{array}$ & $\begin{array}{l}4 \text { cell to B } \\
\text { Uterine horn }\end{array}$ & $<0.3$ & 31.2 & 31.2 & $6.2 \pm 3.1$ \\
\hline $\begin{array}{l}\text { Yonemura } \\
\text { et al } 1996\end{array}$ & Rubber spiral catheter & $\begin{array}{l}\mathrm{M} \text { to } \mathrm{HB} \\
\text { Flushed into } \\
\text { uterine horn }\end{array}$ & 30 or 50 & 64.0 & 64.0 & $3.1 \pm 1.6$ \\
\hline $\begin{array}{l}\text { Riha \& } \\
\text { Vejnar } 2003\end{array}$ & $\begin{array}{c}\text { Al catheter \& silicon } \\
\text { catheter }\end{array}$ & $\begin{array}{c}\text { ExB, H, HB } \\
\text { Body of uterus }\end{array}$ & 5 & $\begin{array}{l}48.0 \\
64.0\end{array}$ & $\begin{array}{l}32.0 \\
64.0\end{array}$ & $\begin{array}{l}6.88 \pm 1.78 \\
8.14 \pm 2.03^{*}\end{array}$ \\
\hline $\begin{array}{l}\text { Riha \& } \\
\text { Vejnar } 2004\end{array}$ & $\begin{array}{c}\text { Al catheter \& silicon } \\
\text { catheter }\end{array}$ & $\begin{array}{c}\mathrm{ExB}, \mathrm{H}, \mathrm{HB} \\
\text { Body of uterus }\end{array}$ & 5 & 69.2 & 69.2 & $7.9 \pm 2.42^{*}$ \\
\hline $\begin{array}{l}\text { Martinez et al } \\
2004\end{array}$ & $\begin{array}{l}\text { Al spirette \& inner } \\
\text { flexible } 1.2 \mathrm{~mm} \\
\text { catheter }\end{array}$ & $\begin{array}{l}M \text { and } B \\
\text { Middle to upper } \\
\text { third of uterine horn }\end{array}$ & 0.7 & 70.8 & 70.8 & $6.9 \pm 0.7$ \\
\hline
\end{tabular}

* from vitrified embryos $\quad M=$ morulae, B - blastocysts, ExB - expanded blastocysts, $H$ - hatching blastocysts, HB - hatched blastocysts.

It would be most desirable to be able to carry out non-surgical transfers without sedation and with the animal standing. It also appears important to deposit the embryos into the uterine horn although some reports indicate that early stage embryos deposited in the body of the uterus migrate into the uterine horns, whereas blastocysts need to be deposited directly into the horn. Litter size may be adversely affected by using large volumes of flushing medium but preg- 
nancy rate appears not to be. Avoiding contamination during the procedure has also been found to be important and methods of eliminating introduction of infectious agents into the uterus need to be considered. The reports do however indicate that the cervix of the sow 3 to 5 days after oestrus is still dilated enough to insert a spirette Al catheter without the need for the use of drugs. None of the reports found a significant difference in success rates comparing gilts with sows.

\section{Conclusions}

Embryo transfer in pigs is now a commercially viable technology for use in the pig industry, especially for the transfer of highly valued genetic material. This is due to advances that have taken place over the last 10 years in cryopreservation of the embryo and non-surgical transfer technology. Commercial embryo transfer programmes using the early stage zona intact embryo have achieved pregnancy rates of $80 \%$ and average litter size of 8.2 piglets born and embryo survival rates in farrowing sows of $29.0 \%$. The improved survival of frozen embryos is due to the use of vitrification in conjunction with specific cryoprotectants, increasing the rate of temperature change by the use of OPS, SOPS, lowering the boiling point of LN2 and/or vitrifying in microdroplets. Similarly non-surgical embryo transfer technology has made it possible to achieve pregnancy rates of around $70 \%$ and $>8$ piglets born. Embryo transfer technology now makes routine international transfer of pig genetic material with minimal risk of disease transmission a reality.

\section{References}

Arav A, Bacci ML and Rubinsky B (1990) Vitrification of immature pig oocytes Proceedings International Pig Veterinary Society Congress Lausanne p 479

Arav A, Zeron $Y$ and Ocheretny A (2000) A new device and method for vitrification increases the cooling rate and allows successful cryopreservation of bovine oocytes Theriogenology 53248

Beebe LFS, Cameron RDA, Blackshaw AW and Keates HL (2005) Changes to porcine blastocyst vitrification methods and improved litter size after transfer Theriogenology 64 879-890

Beebe LFS, Cameron RDA, Blachshaw AW, Higgins A and Nottle MB (2002a) Piglets born from centrifuged and vitrified early and peri-hatching blastocysts Theriogenology 57 2155-2165

Beebe LFS, Cameron RDA, Blackshaw AW and Verrall RG (2002b) Vitrification of zona pellucida intact embryos and birth of piglets using the VitMaster Proceedings of $17^{\text {th }}$ IPVS Congress Ames, lowa USA 1 234

Beebe LFS, Cameron RDA, Blackshaw AW, Higgins A and Nottle MB (2000) Piglets born from vitrified zona intact blastocysts Theriogenology 53249

Beebe LFS, Cameron RDA, Blackshaw AW, Keates $H$ and Nottle MB (2004) Assisted hatching improves post-warming in vitro viability of vitrified porcine embryos Reproduction, Fertility and Development 16164

Berthelot $F$, Martinat-Botte $F$, Perreau $C$ and Terqui $M$ (2001) Birth of piglets after OPS vitrification and transfer of compacted morula stage embryos with intact zona pellucida Reproduction, Nutrition and
Development $41267-272$

Berthelot F, Martinat-Botte F, Locatelli A, Perreau $C$ and Terqui $M$ (2000) Piglets born after vitrification of embryos using the open pulled straw method Cryobiology 41 116-124

Berthelot F, Martinat-Botte F, Perreau C, Locatelli A, Manceau P, Venturi E and Terqui $M(2002)$ The use of an appropriate vitrification medium allows development of $30 \%$ of cryopreserved blastocysts and their birth as live piglets. Pig News and Information $23103 \mathrm{~N}-108 \mathrm{~N}$

Cameron RDA, Beebe LFS, Blackshaw AW and Keates HL (2004) Farrowing rates and litter size following transfer of vitrified porcine embryos into a commercial swine herd Theriogenology 61 1533-1543

Cameron RDA, Beebe LFS, Blackshaw AW, Higgins A and Nottle MB (2000) Piglets born from vitrified early blastocysts using a simple technique Australian Veterinary Journal 78 195-196

Cameron RDA, Durack M, Fogarty R, Putra DKH and McVeigh I (1989) Practical experience with commercial embryo transfer in pigs Australian Veterinary Journal 66 314-317

Cuello C, Gil AM, Parrilla I, Tornel J, Vazquez JM, Roca J, Berthelot $F$, Martinat-Botte $F$ and Martinez EA (2004a) Vitrification of porcine embryos at various developmental stages using different ultra-rapid cooling procedures Theriogenology 62 353-361

Cuello $C$, Berthelot F, Martinat-Botte F, Guillouet $P$, Furstoss, V, Boisseau C, Manceau P, Locatelli A and Martinez EA (2004b) Transfer of vitrified blastocysts from one or two superovulated Large White 
Hyperprolific donors to Meishan recipients: Reproductive parameters at Day 30 of pregnancy Theriogenology $61843-853$

Dinnyes A, Dai Y, Jiang S and Yang X (2000) High developmental rates of vitrified bovine oocysts following parthenogenetic activation, in vitro fertilisation and somatic cell nuclear transfer Biology of Reproduction 63 513-518

Dinnyes A, Kikuchi K, Watanabe A, Fuchimoto D, Iwamoto M, Kaneko H, Noguchi I, Somfai T, Onishi $A$ and Nagai T (2003) Successful cryopreservation of in vitro produced pig embryos by the solid surface vitrification (SSV) method Theriogenology 59299

Dobrinsky JR (1996) Cellular approach to cryo-preservation of embryos Theriogenology 45 17-26

Dobrinsky JR (2000) Cryopreservation of Swine Embryos - Farrowing super cool pigs! In Boar Semen Preservation N pp 99-105 IVth International Conference on Boar Semen Preservation Beltsville, Maryland USA

Dobrinsky JR (2002) Advancements in cryopreservation of domestic animal embryos Theriogenology 57 285302

Dobrinsky JR and Johnson LA (1993) Effect of vitrification media on the in vitro development of porcine embryos Theriogenology 39209

Dobrinsky JR and Johnson LA (1994) Cryopreservation of porcine embryos by vitrification: a study of in vitro development Theriogenology 42 25-35

Dobrinsky JR, Pursel VG, Long CR and Johnson LA (2000) Birth of piglets after transfer of embryos cryopreserved by cytoskeletal stabilisation and vitrification Biology of Reproduction $61564-570$

Edidin $M$ and Petit VA (1977) The effect of temperature on the lateral diffusion of plasma membrane protein. In The freezing of mammalian embryos pp 155-156 Eds K Elliott and J Whelan. Elsevier, Excepta Medica, Amsterdam

Feng S, Zhang Y, Li S, Ma Z, Wang R and Lu D (1991) Piglets from frozen $\left(-20^{\circ} \mathrm{C}\right)$ embryos were born in China Theriogenology 35199

Fujino Y, Yonemura I, Suzuki M and Misumi K (2003) Cryotolerance of porcine embryos - the need for batch-wise assessment Theriogenology 59302

Galvin JM, Killian DB and Stewart ANV (1994) A procedure for successful non surgical embryo transfer in swine Theriogenology 41 1279-1289

Hayashi S, Kobayashi K, Mizumo J, Saitoh K and Hirano $S$ (1989) Birth of piglets from frozen embryos Veterinary Record 125 43-44

Hazeleger W and Kemp B (1994) Farrowing rates and litter size after transcervical embryo transfer in swine Reproduction in Domestic Animals 29 481-487

Hazeleger W and Kemp B (2001) Recent developments in pig embryo transfer Theriogenology 56 13211331

Isachenko V, Folch J, Isachenko E, Nawroth F, Krivokharchenko A, Vajta G, Dattena $M$ and Alabart IL (2003) Double vitrification of rat embryos at different developmental stages using an identical protocol Theriogenology $60 \quad 445-452$
Kashiwazaki N, Ohtani S, Miyamoto K and Ogawa S (1991) Production of normal piglets from hatched blastocysts frozen at $-196^{\circ} \mathrm{C}$ Veterinary Record 128 256-257

Kobayashi S, Tomita M, Pollard JW and Leibo SP (1994) Survival of cryopreserved porcine embryos vitrified in ethylene glycol plus polyvinyl pyrrolidone Theriogenology 41228

Kobayashi S, Takei $M$, Kano $M$, Tomita $M$ and Leibo SP (1998) Piglets produced by transfer of vitrified porcine embryos after stepwise dilution of cryoprotectants Cryobiology 36 20-31

Kobayashi S, Kano M, Takei M and Tajima S (2003) Viability and telomerase activity of porcine embryos vitrified by an ultra-rapid cooling method using the open pulled straw Theriogenology 59304

Kuwayama M, Holm P, Jacobsen $H$, Greve T and Callesen $H$ (1997) Successful cryopreservation of porcine embryos by vitrification Veterinary Record 4365

Lane M, Bavister BD, Lyons EA and Forest KT (1999) Containerless vitrification of mammalian oocytes and embryos Nature Biotechnology 17 1234-1236

Li J, Rieke A, Day BN and Prather RS (1996) Technical note: Porcine non-surgical embryo transfer journal of Animal Science 74 2263-3368

Lindemans W, Sangalli L, Kick A, Earl CR and Fry RC (2004) Vitrification of bovine embryos using the CLV method Reproduction Ferility and Development 16 174

Martinez EA, Caamano JN, Gil MA, Rieke P, McCauley TC, Cantley TC, Vazquez JM, Roca J, Vazquez JL, Didion 8A, Murphy CN, Prather RS and Day BN (2004) Successful non-surgical deep uterine embryo transfer in pigs Theriogenology 61 137-146

Mazur P (1977) Slow-freezing injury in mammalian cells In The freezing of marmmalian embryos pp 19-48 Eds $K$ Elliott and / Whelan. Elsevier Excepta Medica, Amsterdam

Mazur P, Coe KW, Hall JW,Schreuders PD and Mahowald AP (1992) Cryobiological preservation of Drosophila embryos Science 258 1932-1935

Misumi K, Suzuki M, Sato S and Saito N (2003) Successful production of piglets derived from vitrified morulae and early blastocysts using a micro droplet method Theriogenology 60 253-260

Mödl J, Reichenbach HD, Voss W, Zhu J and Brem G (1993) A technique for transcervical transfer of embryos into the uterine horn of gilts $4^{\text {th }}$ International Conference on Pig Reproduction, Missouri, USA p39

Mohr LR and Trounson AO (1981) Structural changes associated with freezing of bovine embryos Biology of Reproduction 25 1009-1025

Nagashima H, Kato Y, Yamakawa H and Ogawa S (1988) Survival of pig hatched blastocysts exposed below $15^{\circ} \mathrm{C}$ lapanese lournal of Animal Reproduction 34 123-131

Nagashima $H$, Kato $Y$, Yamakawa $H$, Matsumoto $T$ and Ogawa $S$ (1989) Changes in freezing tolerance of pig blastocysts in peri-hatching stage lapanese fournal of Animal Reproduction 35 130-133

Nagashima H, Yamahawa $H$ and Niemann $H$ (1992) 
Freezability of porcine blastocysts at different perihatching stages Theriogenology 37 839-850

Nagashima H, Kashiwazaki N, Ashman RJ, Grupen CG, Seamark RF and Nottle MB (1994) Removal of cytoplasmic lipid enhances the tolerance of porcine embryos to chilling Biology of Reproduction 51 618622

Nagashima H, Kashiwazaki N, Ashman RJ, Grupen CG and Nottle MB (1995a) Cryopreservation of porcine embryos Nalure 374416

Nagashima H, Kashiwazaki N, Ashman RJ and Nottle MB (1995b) Improved survival of porcine hatched blastocysts cryopreserved with glycerol and sucrose Journal of Reproduction and Development 41 165170

Nagashima $H$, Cameron RDA, Kuwayama $M$, Young $M$, Beebe L.FS, Blackshaw AW and Nottle MB (1999) Survival of porcine delipated oocytes and embryos after cryopreservation by freezing or vitrification Journal of Reproduction and Development 45 167176

Niemann H (1991) Cryopreservation of ova and embryos from livestock: current status and research needs Theriogenology 35 109-124

Niimura S and Ishida K (1980) Histochemical observations of lipid droplets in mammalian eggs during the early development Japanese Journal of Animal Reproduction $26 \quad 46-49$

Papis K, Shimizu K and Izaike $\mathbf{Y}$ (2000) Factors affecting the survivability of bovine oocytes vitrified in droplets Theriogenology 54 651-658

Parks JE and Ruffing NA (1992) Factors affecting low temperature survival of mammalian oocytes Theriogenology 37 59-73

Polge $C$ (1977) In The freezing of mammalian embryos pp 3-8 Eds K Elliott and J Whelan. Elsevier Excepta Medica, Amsterdam

Polge C and Day BN (1968) Pregnancy following nonsurgical egg transfer in pigs Veterinary Record 82 712

Polge $C$ and Willadsen SM (1978) Freezing eggs and embryos of farm animals Cryobiology $15370-373$

Polge C, Wilmut I and Rowson LEA (1974) Low temperature preservation of cow, sheep and pig embryos Cryobiology 11560

Pollard JW and Leibo SP (1994) Chilling sensitivity of mammalian embryos Theriogenology 41 101-106

Rall WF (1987) Factors affecting the survival of mouse embryos cryopreserved by vitrification Cryobiology $24387-402$

Rall WF and Fahy GM (1985) Ice-free cryopreservation of mouse embryos at $-196^{\circ} \mathrm{C}$ by vitrification Nature 313 573-575

Reichenbach HD, Mödl J and Brem G (1993) Piglets born after transcervical transfer of embryos into recipient gilts Veterinary Record 133 36-39
Riha J and Vejnar J (2003) Laparoscopic and non-surgical transfer of fresh and frozen porcine embryos Czech fournal of Animal Science 48 508-518

Riha J and Vejnar J (2004) Comparison of two vitrification methods for cryopreservation of porcine embryos Czech lournal of Animal Science 49183 189

Sims MM and First NL (1987) Non-surgical embryo transfer in swine lournal of Animal Science 65386

Steponkus PL, Myers SP, Lynch DV, Gardner L, Bronshteyn V, Leibo SP, Rall WF, Pitt RE, Lin TT and MacIntyre RJ (1990) Cryopreservation of Drosophila melanogaster embryos Nature 345 170-172

Thomas JF and Hillman N (1980) The metabolism of exogenous fatty acids by preimplantation mouse embryos developing in vitro fournal of Embryology and Experimental Morphology 56 157-168

Yonemura 1, Fujino $Y$, Irie $S$ and Miura $Y$ (1996) Transcervical transfer of porcine embryos under praclical conditions lournal of Reproduction and Development 42 89-94

van de Lende T and Hazeleger W (1998) New technologies in female reproduction Proceedings $15^{\text {th }}$ IPVS Congress Birmingham, England pp219-223

Vajta G, Booth PJ Holm P, Greve T and Callasen H (1997a) Successful vitrification of early stage bovine in vitro produced embryos with the open pulled straw (OPS) method Cryo Letters 18 191-195

Vajta G, Holm P, Greve T and Callesen H (1997b) Vitrification of porcine embryos using the Open Pulled Straw (OPS) method Veterinaria Scandinavica 38363 366

Vajta G, Holm P, Kuwayama M, Booth PJ, Jacobsen $H$, Greve T and Callesen H (1998) Open Pulled Straw (OPS) vitrification: a new way to reduce cryo-injured of bovine ova and embryos Molecular Reproduction and Development 51 53-58

Weber PK and Young CR (1994) Investigation of cryoprotectant toxicity to porcine embryos Theriogenology 41 1291-1298

Weber PK, McGinnis I.K and Young CR (1992) An evaluation of potential vitrification solutions for cryopreservation of porcine embryos Theriogenology 37321

White B, Montagner M, Mills G, Goncalves P and Christenson $\mathbf{R}$ (2005) Comparison of in vitro development following cryopreservation of Meishan and white cross embryos Reproduction Fertility and Development 17200

Wilmut 1 (1972) The low temperature preservation of mammalian embryos Journal of Reproduction and Fertility 31 513-514 